\title{
Monitoring Prohemostatic Treatment in Bleeding Patients
}

\author{
Marco Ranucci, M.D. ${ }^{1}$ Ekaterina Baryshnikova, B.D. ${ }^{1}$ Dionisio Colella, M.D. ${ }^{2}$ \\ ${ }^{1}$ Department of Cardiothoracic-Vascular Anesthesia and Intensive \\ Care, IRCCS Policlinico S.Donato, Milan, Italy \\ 2 Department of Anesthesia and Intensive Care, Policlinico Tor Vergata, \\ Tor Vergata University of Rome, Rome, Italy \\ Address for correspondence and reprint requests Marco Ranucci, \\ M.D., Director of Clinical Research in the Department of Anesthesia \\ and Intensive Care, IRCCS Policlinico S.Donato, Via Morandi 30, 20097 \\ San Donato Milanese, Milan, Italy (e-mail: cardioanestesia@virgilio.it).
}

Semin Thromb Hemost 2012;38:282-291.

\begin{abstract}
\section{Keywords}

- thromboelastography

- platelet function analyzers

- fresh frozen plasma

- coagulation factors

- desmopressin
\end{abstract}

Acutely bleeding patients are commonly found in the trauma and major surgery scenarios. They require prompt and effective treatment to restore an adequate hemostatic pattern, to avoid serious and sometimes life-threatening complications. Different prohemostatic treatments are available, including allogeneic blood derivatives (fresh frozen plasma, platelet concentrates, and cryoprecipitates), prothrombin complex concentrates, specific coagulation factors (fibrinogen, recombinant factor XIII, recombinant activated factor VII), and drugs (protamine for patients under heparin treatment, desmopressin, antifibrinolytics).

For decades, prohemostatic treatment of the acutely bleeding patient was based on empirical strategies and clinical judgment, both in terms of a correct diagnosis of the mechanism(s) leading to bleeding, and of an assessment of the effects of the treatment. This empirical strategy may lead to excessive or unnecessary use of allogeneic blood products, as well as to an incorrect, inefficacious, or even dangerous treatment. Different monitoring devices are nowadays available for guiding the diagnostic and therapeutic decision-making process in an acutely bleeding patient. This review addresses the available tools for monitoring prohemostatic treatment of the bleeding patient, with a specific respect for point-of-care tests (thromboelastography, thromboelastometry, platelet function tests, and heparin monitoring systems) at the light of the existing evidence.

Acute, severe bleeding in the setting of major surgical operations or trauma is a life-threatening evenience that requires an effective and timely treatment.

Prohemostatic treatment of acutely bleeding patients is based on (1) the administration of allogeneic blood derivatives, such as fresh frozen plasma (FFP), platelet concentrates, and cryoprecipitates; (2) specific drugs (antifibrinolytics, desmopressin, protamine); (3) prothrombin complex concentrates (PCC); and (4) isolated coagulation factors such as recombinant factor XIII ( $r F X I I I)$, recombinant activated factor VII (rFVIIa), and fibrinogen.

published online February 18, 2012
Issue Theme Prohemostatic Interventions: What's New? Guest Editor, Marcel Levi, M.D., Ph.D.
In the setting of trauma and surgical operations, a correct use of the above strategies requires a diagnostic procedure to identify which mechanism(s) underlie the bleeding process, and a monitoring process to identify the efficacy of the different therapeutic strategies. As a matter of fact, different mechanisms may determine the bleeding process: (1) the loss of platelets and/or an impairment of platelet function due to the preoperative use of antiplatelet agents or contact with foreign surfaces of the cardiopulmonary bypass (CPB) circuit, (2) incomplete neutralization of heparin after cardiac operations, (3) hyperfibrinolysis due to enhanced activity of the
Copyright (c) 2012 by Thieme Medical Publishers, Inc., 333 Seventh Avenue, New York, NY 10001, USA. Tel: +1(212) 584-4662
DOI http://dx.doi.org/ 10.1055/s-0032-1302443. ISSN 0094-6176. 
tissue plasminogen activator, and (4) low levels of coagulation factors due to blood loss, hemodilution, consumption, or preoperative use of oral anticoagulants.

The need for a monitoring process of the therapeutic interventions derives from both efficacy and safety considerations. Many of the drugs used to treat massive bleeding may in fact determine prothrombotic complications. At the same time, the clinical environment (operating room, emergency room, or intensive care unit) where massive bleeding is generally identified and treated, and the urgency of treatment of a potentially life-threatening condition, make mandatory the use of point-of-care tests for monitoring the effects of the therapeutic strategies applied.

The following part of this review article will therefore address the monitoring tools available to correctly assess the efficacy of the therapeutic strategies in the clinical setting of bleeding in trauma and surgical patients.

\section{Substitution Therapy (Nonspecific Coagulation Factors Administration)}

Coagulation factors are usually administered to acutely bleeding patients through the transfusion of FFP or cryoprecipitates. PCC offer the advantage of avoiding the volume overload and the transfusion-associated adverse reactions attributed to FFP, at the expenses of a higher cost.

Whatever product is used, the administration of nonspecific coagulation factors relies on the hypothesis that the patient is bleeding due to a reduced concentration of one or more factors, usually due to blood loss or consumption. Patients under warfarin treatment may of course face severe bleeding under trauma or major surgical operation conditions, due to the drug-induced impairment in the hepatic synthesis of coagulation factors.

The classical laboratory tests measuring the coagulation factors activity include the prothrombin time (PT) and the derived international normalized ratio (INR). However, they are usually applied to test chronic anticoagulation with warfarin, or the reversal of warfarin treatment with PCC, rather than to diagnose the nature of an acute bleeding. The ideal laboratory test to assess the ability of the patient to generate thrombin, and therefore the adequacy of the coagulation factors concentration to achieve a correct hemostasis, is the thrombin generation test (TGT). TGT is based on chromogenic thrombin detection in a plasma assay where specific triggers (tissue factor) are added. From the resulting thrombin generation curve (-Fig. 1), the parameters of TGT are derived: lag-time, peak height, time to peak, and the area under curve (AUC) (endogenous thrombin potential, ETP). The TGT provides a valuable information in case of inherited or acquired coagulation factors deficiency; it can be used to assess the effects of replacement therapy in inherited coagulation factors deficiency; to assess the reversal of warfarininduced coagulation factors deficiency with PCC or FFP/ cryoprecipitates, and even to measure the effects of heparin treatment and the efficacy of heparin reversal. ${ }^{1-4}$ Theoretically, it is the ideal test to diagnose the nature of a bleeding due to lack of coagulation factors, and to monitor the efficacy of the coagulation factors replenishment. Unfortunately, it is not a routine test available in all the hospital clinical laboratories, and requires time. Therefore, its utility is limited in the setting of trauma patients or major surgical operations.



Figure 1 Thrombin generation test. 

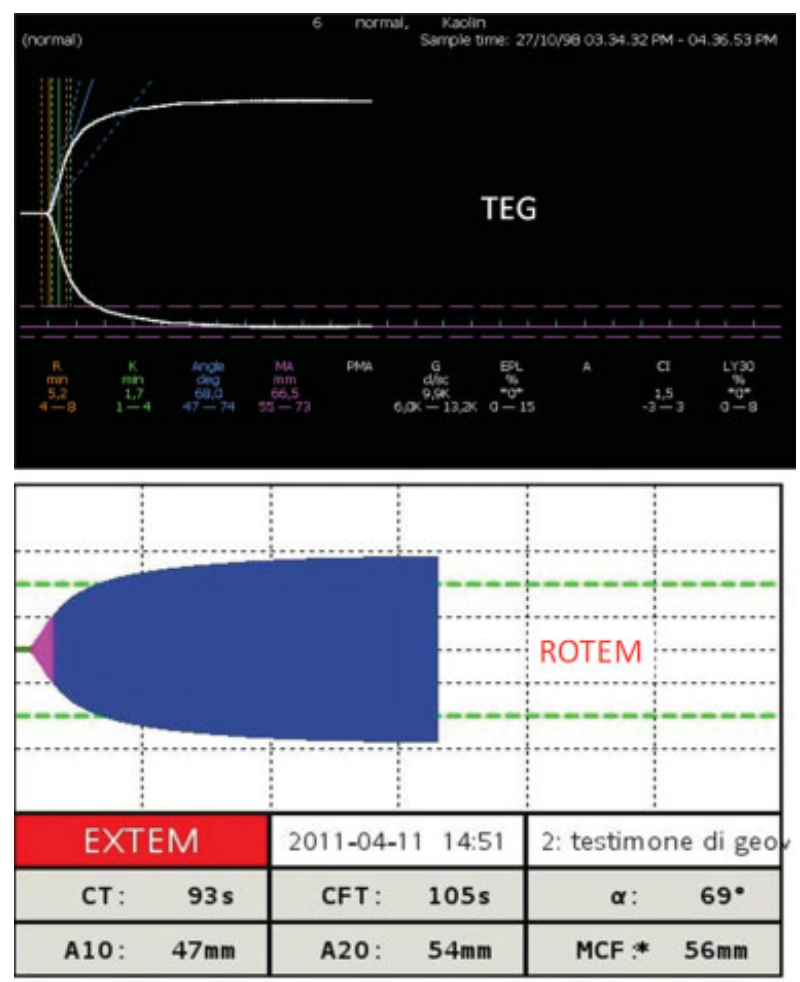

Figure 2 Thromboelastography (TEG) and thromboelastometry (ROTEM) standard tests.

Whenever a rapid test for the activity of coagulation factors is required, useful information may derive from the analysis of the viscoelastic properties of the clot. This can be achieved using the point-of-care tests thromboelastography (TEG, Haemoscope Corp., Niles, IL) or thromboelastometry (ROTEM, Pentapharm GmbH, Munich, Germany). Both tests use whole blood, activated with kaolin (TEG) or intrinsic (InTEM) or extrinsic (ExTEM) pathway activators for ROTEM. The resulting tracings ( $\mathbf{- F i g . ~} \mathbf{2}$ ) provide some parameters related to the viscoelastic properties of the clot. Coagulation factors activity is defined by the reaction time (R) in the TEG or the clot time (CT) in the ROTEM. In both cases, these times represent the lag between the start of the test and the first appearance of a physically detectable clot, and therefore reflect the time to fibrin generation and the coagulation factors activity.

$\mathrm{R}$ and $\mathrm{CT}$ are prolonged in case of inherited as well as acquired coagulation factors deficiencies. A normalization of these parameters after FFP, cryoprecipitates, and PCC is indicative for a reestablished adequate coagulation factors activity. TEG- or ROTEM-guided diagnostic and therapeutic approaches have been successfully applied in cardiac surgery, ${ }^{5-7}$ liver surgery and transplantation, ${ }^{8}$ and trauma patients with massive bleeding. ${ }^{9-13}$

An adequate correction of coagulation factors deficiencies does not only induce the normalization of the time to fibrin generation, but even an increase of the clot strength. This is defined as the maximum amplitude (MA) in the TEG or the maximum clot firmness (MCF) in the ROTEM (-Fig. 2). However, it should be considered that both the MA and the
MCF reflect the interaction between fibrin and platelets in determining the clot strength. Therefore, even an adequate coagulation factors activity may result in poor clot strength in case of low platelet count or function. In these cases, the R and CT are normalized after correction with FFP, cryoprecipitates, or PCC, but the MA and MCF remain low. Adequate and more specific tests for determining the contribution of fibrin and platelets to the clot strength are available and will be addressed in the following parts of this article.

\section{Fibrinogen}

The use of fibrinogen for the treatment of bleeding in trauma or surgical settings has been recently reevaluated. ${ }^{14-16}$ Fibrinogen levels may be abnormally low in case of consumption due to massive bleeding, or as a consequence of prolonged CPB in cardiac surgery. ${ }^{17,18}$ Measurement of fibrinogen concentration may be useful for the diagnosis of bleeding due to a low fibrinogen level. Standard laboratory methods are generally based on photo-optical measurements and Clauss method. However, this measurement suffers from a wide between-laboratory variability. ${ }^{19}$

Both the TEG and the ROTEM provide point-of-care testing of the fibrinogen adequacy to contribute to the clot strength. The MA and the MCF are parameters related to the clot strength, and therefore depend on both the fibrinogen and platelet contribution. To separate the platelet contribution, different platelet inhibitors may be used. In these tests (functional fibrinogen for the TEG or FibTEM for the ROTEM) platelets are inhibited with abciximab or cytochalasin D, respectively. By comparing the MA or MCF at the standard TEG/ROTEM with the correspondent values after platelet inhibition (-Fig. 3), the contribution of fibrinogen to the total clot strength may be assessed. ${ }^{17,20,21}$

Both TEG and ROTEM measurements of fibrinogen activity have been widely used for monitoring fibrinogen replenishment in the setting of massive bleeding due to trauma and surgery. ${ }^{14-18,20}$ FibTEM MCF correlates with direct measurements of fibrinogen concentration before fibrinogen administration; but after fibrinogen administration the correlation is considerably worse. ${ }^{22}$ At present there is not yet a gold standard for point-of-care measurement of fibrinogen and reference values for establishing a fibrinogen-based treatment are still debated. Moreover, some authors have highlighted that both abciximab and cytochalasin D may not completely blunt the platelet-specific effect on MA or $\mathrm{MCF}^{23}$ therefore raising doubts on the reliability of the measurement of the relative fibrinogen contribution to the clot strength.

\section{rFVIla}

rFVIIa treatment in patients with massive bleeding is a wellrecognized life-saving strategy, which finds its usual scenario in trauma, major orthopedic or urologic operations, liver resection or transplantation, and major cardiac operations. ${ }^{24-29}$ A recent meta-analysis demonstrated its efficacy in different surgical scenarios at a dose of at least $50 \mu \mathrm{g} / \mathrm{kg}$. ${ }^{30}$ rFVIIa treatment is, however, associated with the risk of thromboembolic complications. ${ }^{31,32}$ rFVIIa promotes a 

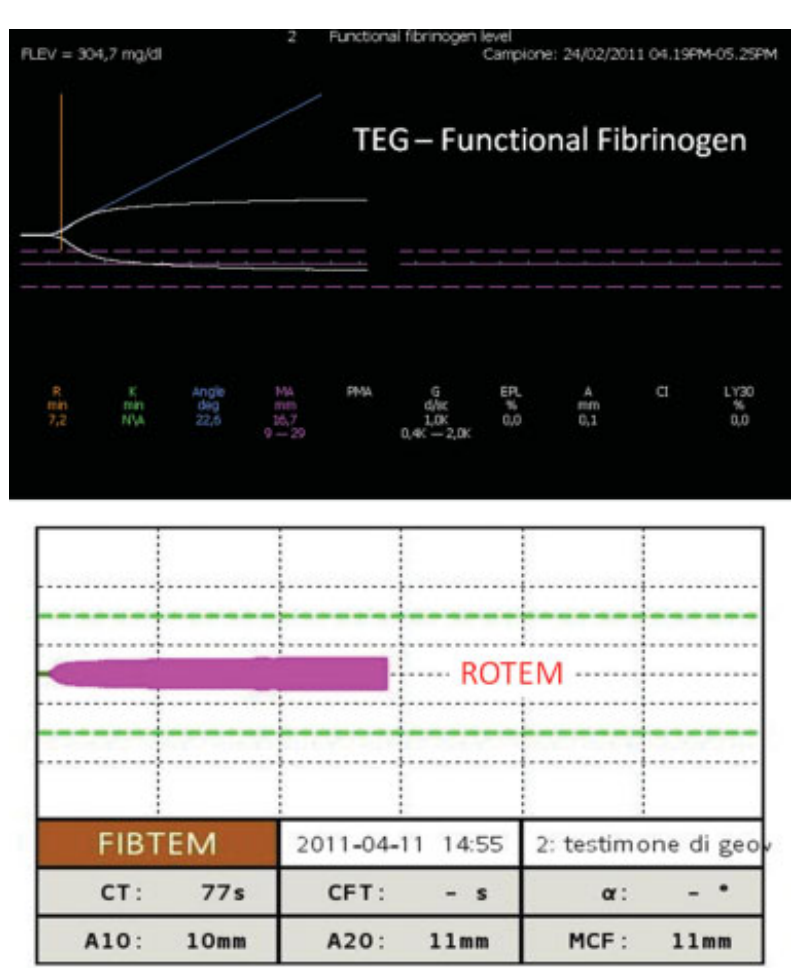

Figure 3 Functional fibrinogen (TEG) and FibTEM (ROTEM) tests for fibrinogen concentration.

thrombin burst, and therefore its effects may be measured using direct or indirect markers of thrombin generation. Within this domain, the standard PT and INR are normalized after rFVIIa administration. TGT is very sensitive to the action of rFVIIa, ${ }^{33}$ but as already observed it is not a routine test in acutely bleeding patients. Both TEG and ROTEM are sensitive to rFVIIa administration, usually demonstrating a dose-dependent decrease of the $\mathrm{R}$ and $\mathrm{CT}$, and a correspondent increase of the MA and MCF. However, this response seems much more evident when rFVIIa is used to treat patients with inherited coagulation factors defects ${ }^{34-37}$ than in patients with acquired defects. A study performed in the setting of cardiac surgery demonstrated that after rFVIla administration in patients with severe, refractory postoperative bleeding, the TEG parameters did not significantly change before and after treatment both in responders and nonresponders. ${ }^{38}$ Conversely, pretreatment TEG parameters were closer to the normal values in the responders than in the nonresponders. This information introduces a very important concept for rFVIIa treatment: rFVIIa induces a thrombin burst, which in turn triggers fibrin formation and fibrin-platelet interaction, finally forming a stable clot. However, when the patient is lacking the factors that contribute to the clot formation downstream thrombin generation (fibrinogen, FXIII, and platelets), rFVIIa may be inefficacious. Under these circumstances, TEG and ROTEM may be useful in optimizing the pretreatment coagulation profile of the patient, but have a limited role for monitoring the efficacy of the therapy. Finally, rFVIIa treatment is not based on a fixed-dose regimen, and some patients may require supplemental doses after the first loading dose. It is possible that the use of point-of-care tests such as the TEG or the ROTEM may be useful to avoid excessive doses with the risk of generating thromboembolic complications.

\section{rFXIII}

rFXIII has been recently added to the therapeutic armamentarium for the bleeding patient. ${ }^{39}$ At present, no clear indications exist for FXIII replenishment. The theoretical basis for this treatment is the presence of a weak and unstable clot, due to a lack of FXIII, and consequent limited conversion of fibrin monomer to stable fibrin polymer. However, a recent phase-II trial on rFXIII supplementation in cardiac surgery did not demonstrate any efficacy of the drug in reducing the transfusion rate nor other bleeding-related outcomes (communication from Novo Nordisk released on April 28, 2011).

Some studies have demonstrated, in in vitro models, that low levels of FXIII are detectable with ROTEM (low MCF, increased clot formation time and lysis) ${ }^{40}$ and that the administration of rFXIII induces an increased clot firmness with increased MCF and reduced clot formation time. ${ }^{41}$ Therefore, it is reasonable to consider that clot firmnessrelated parameters of TEG and ROTEM may be useful for guiding and monitoring the treatment with rFXIII.

\section{Protamine Reversal of Heparin}

After cardiac operations with or without $\mathrm{CPB}$, an incomplete reversal of heparin may result in post-CPB bleeding. However, even a protamine sulfate overdose may inhibit the coagulation system. ${ }^{42,43}$ The usual laboratory test to measure the heparin effect are the activated partial thromboplastin time, or the anti-Xa activity. Both tests are impractical under emergency conditions and whenever a rapid answer is required.

Point-of-care monitoring tools for assessing the correct heparin reversal include the standard activated clotting time (ACT), indirect heparin monitoring systems (HMS, Medtronic Inc., Minneapolis, MN, and others), TEG, and ROTEM. The standard ACT is the most commonly used. Unfortunately, there is a big deal of evidence that the correlation between ACT and heparin concentration is poor. ${ }^{44-46}$ Therefore, an ACT value back to the preoperative is not per se a guarantee that heparin has been totally reversed. The heparin monitoring systems provide more reliable information as they are based on an in vitro test of different protamine concentrations, allowing a precise determination of the protamine dose required for a complete heparin reversal, and avoiding a protamine overdose. Some studies have highlighted that the use of this device to assess the protamine dose leads to the administration of less protamine than the conventional dose based on a fixed ratio between heparin and protamine dose. ${ }^{47,48}$

TEG and TEM are not designed to identify the correct protamine dose, but provide useful information with respect to the presence of residual circulating heparin after protamine reversal in a bleeding patient. The time from the beginning of the test until the initial fibrin generation ( $R$ in 


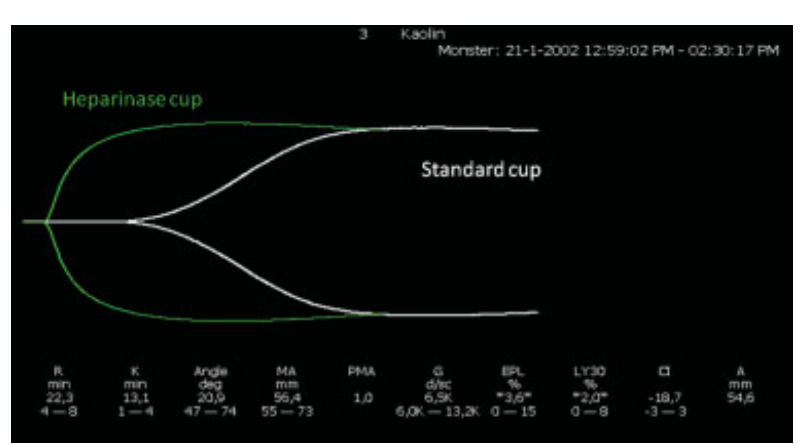

Figure 4 Residual heparin effect at thromboelastography (TEG) with and without heparinase.

the TEG or CT in the TEM) may be tested in whole blood with or without heparinase. The presence of a shorter R or CT in the blood tested with heparinase is suggestive for an incomplete heparin reversal (-Fig. 4), and this concept has been incorporated in different algorithms for the treatment of a postcardiac surgery bleeding patient. ${ }^{49-53}$

\section{Platelet Transfusions}

Platelet concentrates may be used for the treatment of bleeding in trauma or major surgery, whenever the bleeding mechanism is likely to be related to severe thrombocytopenia or platelet dysfunction. Even if there is no evidence-based information, platelet transfusions may be indicated in bleeding surgical patients when the platelet count is less than $50,000 / \mu \mathrm{L}^{54-56}$ This therapeutic approach, based on the platelet count, is difficult to monitor, even because the most commonly used point-of-care tests for platelet function in whole blood are impaired in case of thrombocytopenia.

However, platelet transfusions may be necessary even in patients with acquired platelet dysfunction. In patients under thienopyridine treatment, or after $\mathrm{CPB}$, despite a normal or moderately decreased platelet count, the platelet aggregability is impaired, and severe bleeding may occur. ${ }^{54,57}$ As thienopyridine inhibition of the P2Y12 platelet receptor is irreversible, platelet transfusions may be needed to provide new and relatively intact platelets for the hemostatic process.

The standard laboratory method to measure platelet aggregability is the light transmission aggregometry. ${ }^{58}$ This test is usually applied in inherited or acquired bleeding disorders, and to assess the effects of antiplatelet drugs. The test is performed on platelet-rich and platelet-poor plasma, and therefore requires time and resources. For this reason, it has no role in the diagnosis of acute bleeding in trauma and surgical patients.

In this subset of patients, platelet function tests may provide (1) an assessment of the preoperative level of platelet aggregability and (2) a monitoring tool for assessing the efficacy of platelet transfusions in restoring an acceptable global platelet function.

Conventionally, platelet function has been assessed with the bleeding time. However, the bleeding time does not identify patients that are likely to bleed excessively after surgery, and does not identify those patients who have recently assumed antiplatelet agents. ${ }^{59}$

The PFA-100 (Siemens Healthcare Diagnostics Inc., Deerfield, IL) measures a closure time for the platelets to occlude a micropore in a membrane, after stimulation with collagenepinephrine (for testing aspirin effects) or adenosine diphosphate (ADP; for testing thienopyridine effects). The closure time is prolonged in patients under antiplatelet agents (unless they are resistant to aspirin or thienopyridines $)^{60,61}$; platelet dysfunction after СРB may be detected as well, and some authors suggest that PFA-100 may identify patients who will benefit from platelet transfusion after cardiac surgery. ${ }^{62}$

Multielectrode aggregometry (MEA) is achieved with the Multiplate (Dynabyte, Munich, Germany). This device measures the time-dependent changes of electrical impedance between two electric filaments, using whole blood previously anticoagulated with hirudin, and after stimulation with specific agonists (arachidonic acid, Aspi test; ADP, ADP test; thrombin receptor-activating peptide, TRAP test). The platelet aggregometric properties are expressed in terms of AUC obtained by plotting electrical impedance versus time (-Fig. 5). MEA is sensitive to the action of aspirin, thienopyridines, and glycoprotein (GP) IIb-IIla inhibitors, ${ }^{63,64}$ and the AUC value at the ADP test in patients receiving thienopyridines before cardiac operations correlates with postoperative bleeding and need for platelet transfusions. ${ }^{65}$

Other available point-of-care platelet function analyzers include the Ultegra (Accumetrics, San Diego, CA), the Plateletworks (Helena Laboratories, Beaumont, TX), and other instruments which provide a measurement of platelet aggregability under different conditions, basically exploring drug-induced platelet dysfunction.

TEG, but not ROTEM, may be used to assess platelet function, through the modified technique of platelet mapping (PM). In both TEG and ROTEM, the parameters MA and MCF reflect the clot strength derived from fibrinogen and platelet interaction. However, standard TEG is unable to detect aspirin or thienopyridine-induced platelet dysfunction, because of the kaolin activation of whole blood. Kaolin determines a thrombin burst, and thrombin is one of the most powerful platelet activators. Thrombin-induced platelet aggregation is determined by the activation of the protease-activated receptors (PAR) 1 (high affinity) and 4 (low affinity). PAR activation actually bypasses both thromboxane and ADPdependent receptors, therefore exerting a maximal platelet aggregation even in presence of aspirin and/or thienopyridines. Under these conditions, and despite drug-induced platelet inhibition, the MA tract is normal.

To overcome this problem, TEG-PM applies a complex diagnostic pathway, which is based on the following steps ${ }^{1}$ : determination of the maximal clot strength (MA) with standard kaolin activation ${ }^{2}$; determination of pure fibrin-based clot strength (MA) using heparin to block thrombin and a novel activator (FXIIIa plus reptilase), where reptilase cleaves fibrinogen releasing fibrinopeptide $\mathrm{A}$ and generating fibrin (without activating platelets); ${ }^{3}$ and determination of the contribution of activated platelets (MA) using heparin, novel 


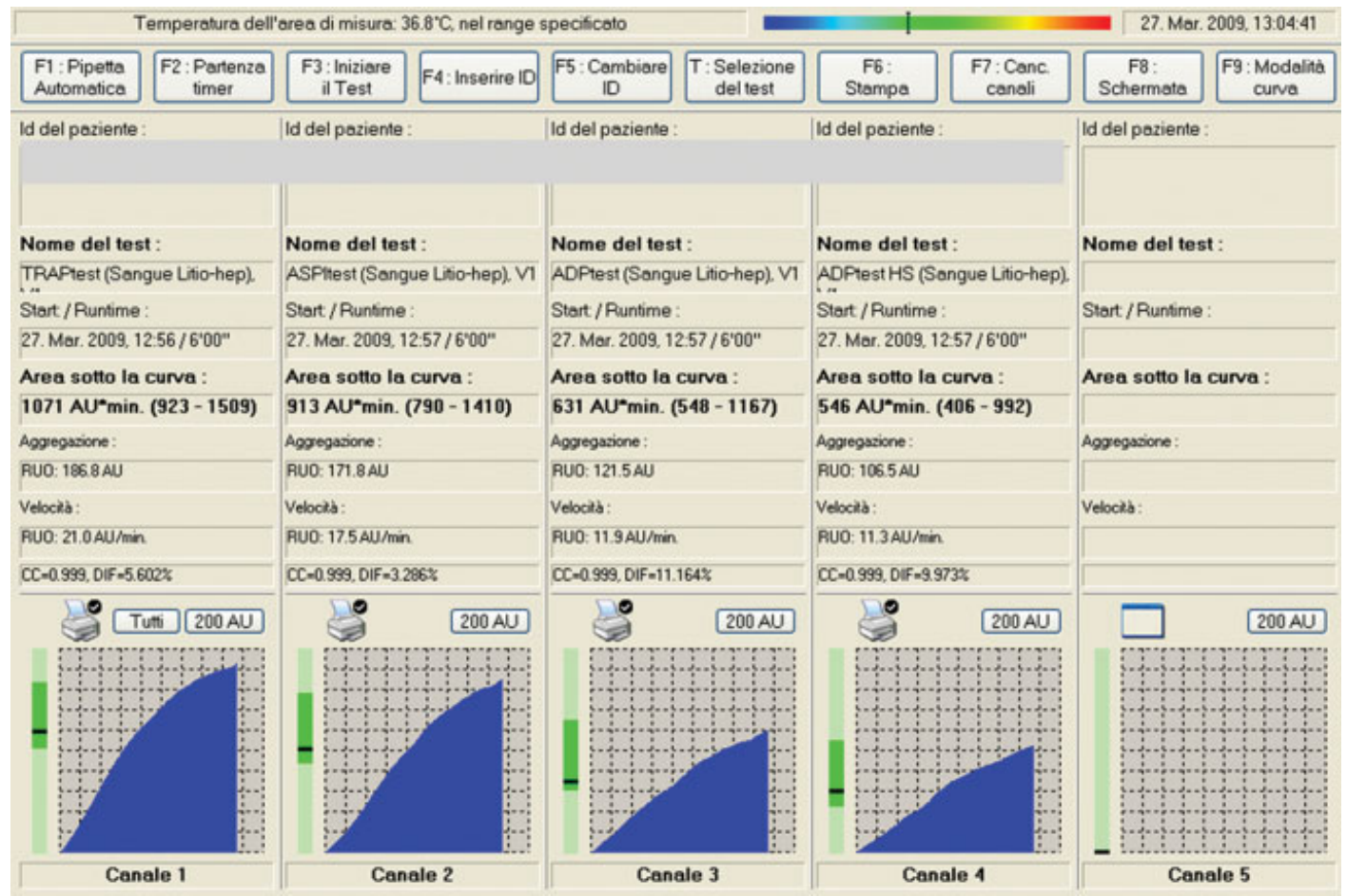

Figure 5 Multiple electrode aggregometry with different platelet activators.

activator, plus arachidonic acid (for testing aspirin inhibition) or ADP (for testing thienopyridines inhibition). Drug-derived platelet inhibition is calculated as the ratio between MA obtained at step 3 divided by the difference between MA at step 1 and MA at step 2 (-Fig. 6 ).

TEG-PM is validated as a tool for measuring the effects of antiplatelet agents, ${ }^{66,67}$ and for identifying patients at risk for postoperative bleeding in cardiac surgery. ${ }^{68}$ Although there is not a strong validation of this concept, it is reasonable that platelet function point-of-care tests may be useful in identifying patients at risk for severe bleeding and who will benefit from platelet concentrate transfusions. Their role in assessing the efficacy of platelet concentrates transfusions has not yet been fully established.

\section{Desmopressin (DDAVP) for the Treatment of Platelet Dysfunction}

DDAVP induces release of large multimers of von Willebrand factor, which promotes platelet adhesion to the vessel wall,

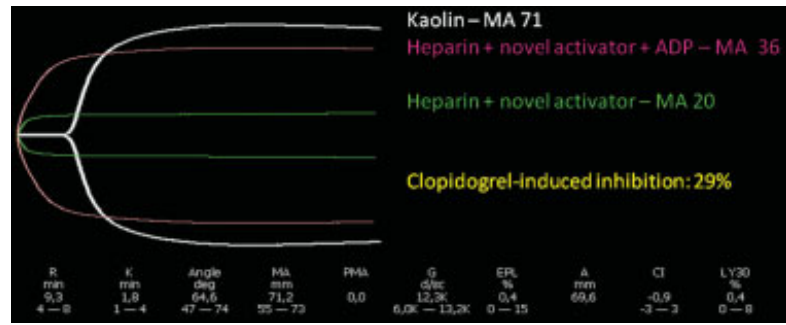

Figure 6 Thromboelastography (TEG) platelet mapping. and indirectly, platelet aggregation. Although its use is still a matter of debate, this treatment gained new attention in the present era characterized by the extensive use of strong antiplatelet agents (ticlopidine, clopidogrel, and prasugrel) for the prevention of native coronary vessels and/or coronary stent thrombosis in patients with coronary artery disease.

The efficacy of DDVAP treatment in enhancing platelet function may be assessed with many different point-of-care tests dedicated to platelet function assessment.

Different studies have highlighted that after DDVAP treatment $(0.3 \mu \mathrm{g} / \mathrm{kg})$ the closure time at the PFA-100 is significantly reduced. ${ }^{69,70}$ Being based on the shear-stress induced platelet adhesion to a foreign surface, this test is probably the most sensitive to assess the effects of DDAVP treatment.

Recently, one study ${ }^{71}$ demonstrated that MEA is effective in assessing DDAVP-induced enhancement of platelet function in the setting of $\mathrm{CPB}$-induced platelet dysfunction. Aspi test, ADP test, and TRAP test all demonstrated a significant increase in the AUC after DDAVP administration. Less information is available for other platelet function point-of-care tests as monitoring tools for DDAVP therapy.

As previously explained, conventional TEG or TEM have limited ability in detecting platelet function under conditions of pharmacological inhibition or stimulation. However, the modified TEG-PM may be used to assess the efficacy of desmopressin in patients pretreated with clopidogrel, ${ }^{72}$ but limited evidence is available.

\section{Antifibrinolytics}

Hyperfibrinolysis occurs when the balance between fibrinolytic activators and inhibitors is altered. ${ }^{73}$ Bleeding due to 
hyperfibrinolysis may be found in chronic liver disease, liver surgery, trauma, and cardiac surgery. ${ }^{74-76}$ However, every clinical condition characterized by increased thrombin generation may trigger hyperfibrinolysis.

Different antifibrinolytic drugs have been used to prevent or control bleeding when hyperfibrinolysis is suspected. Aprotinin was a first-line choice especially in cardiac surgery until a few years ago ${ }^{76}$ but is now available in the market in few countries only. Tranexamic acid (TXA) and epsilon-aminocaproic acid are synthetic antifibrinolytics presently in use, but other novel antifibrinolytics will be probably released in the near future.

Diagnosing hyperfibrinolysis and monitoring antifibrinolytic therapy is a clinical challenge. Theoretically, tissue plasminogen activity is the best marker of hyperfibrinolysis, but its measurement is not a routine in clinical practice. Fibrin degradation products (usually D-dimers) are used as a quick marker of increased fibrinolytic activity; however, they are always increased in the postoperative patient, and no clear cut-off values are available.
Both TEG and ROTEM may be used as point-of-care tests for diagnosing hyperfibrinolysis and guiding antifibrinolytic treatment. ${ }^{77}$ The assessment of fibrinolysis with the TEG is based on the time kinetic of clot destruction (LY30), as measured from the decreasing amplitude of the MA after reaching a peak value. A similar measurement is offered by the ROTEM ( $\left.\mathrm{CLI}_{30}\right)$. The ROTEM provides a more specific test for hyperfibrinolysis (APTEM). In the APTEM, the parameters obtained at the standard ExTEM are compared with the parameters obtained after in vitro inhibition of fibrinolysis using aprotinin. In trauma patients a recent study could identify cut-off values for the ExTEM and the APTEM that were predictive for hyperfibrinolysis with a specificity of $100 \%$ and a sensitivity ranging from 75 to $100 \%{ }^{77}$

The antifibrinolytic treatment of the bleeding patient suffers from a considerable lack of standardization in terms of dosage. TXA is probably the most widely used agent. In cardiac surgery, it is used as a prophylactic treatment for bleeding at a dose which may range from $2 \mathrm{~g}$ to more than $10 \mathrm{~g}$, and the effective dose with the least adverse effects is

Table 1 Prohemostatic Treatments with the Relative Diagnostic and Monitoring Techniques Available

\begin{tabular}{|c|c|c|c|}
\hline Treatment & Conventional Laboratory Tests & Specific Laboratory Tests & Point-of-Care Tests \\
\hline \multirow[t]{2}{*}{ FFP, cryoprecipitates, PCC } & PT & Thrombin generation & TEG \\
\hline & INR & & ROTEM \\
\hline \multirow[t]{2}{*}{ Fibrinogen } & Fibrinogen (Clauss) & - & TEG (functional fibrinogen) \\
\hline & & & ROTEM (FibTEM) \\
\hline \multirow[t]{2}{*}{ rFVIla } & PT & Thrombin generation & TEG \\
\hline & INR & & ROTEM \\
\hline \multirow[t]{2}{*}{ rFXIII } & - & - & TEG \\
\hline & & & ROTEM \\
\hline \multirow[t]{4}{*}{ Protamine reversal of heparin } & APTT & Antifactor-Xa activity & ACT \\
\hline & & & HMS \\
\hline & & & TEG (w/o heparinase) \\
\hline & & & ROTEM (HepTEM) \\
\hline \multirow[t]{5}{*}{ Platelet concentrates } & Platelet count & $\begin{array}{l}\text { Light transmission } \\
\text { aggregometry }\end{array}$ & PFA-100 \\
\hline & Bleeding time & & Multiplate \\
\hline & & & Ultegra \\
\hline & & & Plateletworks \\
\hline & & & TEG (platelet mapping) \\
\hline \multirow[t]{3}{*}{ Desmopressin } & Bleeding time & $\begin{array}{l}\text { Light transmission } \\
\text { aggregometry }\end{array}$ & PFA-100 \\
\hline & & & Multiplate \\
\hline & & & TEG (platelet mapping) \\
\hline \multirow[t]{2}{*}{ Antifibrinolytics } & D-dimers & Tissue plasminogen activity & TEG \\
\hline & & & ROTEM (APTEM) \\
\hline
\end{tabular}

FFP, fresh frozen plasma; PCC, prothrombin complex concentrates; PT, prothrombin time; TEG, thromboelastography; INR, international normalized ratio; ROTEM; rotation thromboelastometry; rFVIla, recombinant activated factor VII; rFXIII, recombinant factor XIII; APTT, activated partial thromboplastin time; ACT, activated clotting time; PFA, platelet function analyzer. 
still unknown. ${ }^{78}$ Given this scenario of uncertainty, monitoring the antifibrinolytic treatment is probably useful to avoid under or overdosage, and TEG or ROTEM are the most useful instruments in the setting of trauma and surgical patients with massive bleeding. ${ }^{73}$

\section{Conclusions}

Prohemostatic treatment of the bleeding patient has been empirically performed for decades. Monitoring prohemostatic treatments is certainly an attempt to provide a more rational approach to a complex matter. However, despite the possibility to measure many different parameters related to the hemostatic system ( $\mathbf{- T a b l e ~} \mathbf{1}$ ), there is still little evidence available with respect to the ideal way of monitoring prohemostatic interventions in the setting of an acutely bleeding patient. Point-of-care tests may certainly represent an important step in the direction of a nonempiric treatment of the bleeding patient. Coagulation parameters obtained with point-of-care tests correlate well with many acquired coagulation system disturbances, however, their changes after prohemostatic treatments are not yet validated as monitoring tools for efficacy of the treatment itself.

\section{References}

1 van Veen JJ, Gatt A, Makris M. Thrombin generation testing in routine clinical practice: are we there yet? Br J Haematol 2008;142 (6):889-903

2 Al Dieri R, Peyvandi F, Santagostino E, et al. The thrombogram in rare inherited coagulation disorders: its relation to clinical bleeding. Thromb Haemost 2002;88(4):576-582

3 al Dieri R, Alban S, Béguin S, Hemker HC. Thrombin generation for the control of heparin treatment, comparison with the activated partial thromboplastin time. J Thromb Haemost 2004;2(8):13951401

4 Devreese K, Peerlinck K, Arnout J, Hoylaerts MF. Laboratory detection of the antiphospholipid syndrome via calibrated automated thrombography. Thromb Haemost 2009;101(1):185196

5 Avidan MS, Alcock EL, Da Fonseca J, et al. Comparison of structured use of routine laboratory tests or near-patient assessment with clinical judgement in the management of bleeding after cardiac surgery. Br J Anaesth 2004;92(2):178-186

6 Shore-Lesserson L, Manspeizer HE, DePerio M, Francis S, VelaCantos F, Ergin MA. Thromboelastography-guided transfusion algorithm reduces transfusions in complex cardiac surgery. Anesth Analg 1999;88(2):312-319

7 Spiess BD, Tuman KJ, McCarthy RJ, DeLaria GA, Schillo R, Ivankovich AD. Thromboelastography as an indicator of post-cardiopulmonary bypass coagulopathies. J Clin Monit 1987;3(1):25-30

8 Cerutti E, Stratta C, Romagnoli R, et al. Thromboelastogram monitoring in the perioperative period of hepatectomy for adult living liver donation. Liver Transpl 2004;10(2):289-294

9 Brohi K. Diagnosis and management of coagulopathy after major trauma. Br J Surg 2009;96(9):963-964

10 Selby R, Geerts W, Ofosu FA, et al. Hypercoagulability after trauma: hemostatic changes and relationship to venous thromboembolism. Thromb Res 2009;124(3):281-287

11 Johansson PI. Hemostatic strategies for minimizing mortality in surgery with major blood loss. Curr Opin Hematol 2009;16 (6):509-514
12 Johansson PI, Bochsen L, Stensballe J, Secher NH. Transfusion packages for massively bleeding patients: the effect on clot formation and stability as evaluated by thrombelastolastograph (TEG). Transfus Apher Sci 2008;39;3-8

13 Johansson PI, Stensballe J. Effect of Haemostatic Control Resuscitation on mortality in massively bleeding patients: a before and after study. Vox Sang 2009;96(2):111-118

14 Schöchl H, Nienaber U, Maegele M, et al. Transfusion in trauma: thromboelastometry-guided coagulation factor concentratebased therapy versus standard fresh frozen plasma-based therapy. Crit Care 2011;15(2):R83

15 Solomon C, Cadamuro J, Ziegler B, et al. A comparison of fibrinogen measurement methods with fibrin clot elasticity assessed by thromboelastometry, before and after administration of fibrinogen concentrate in cardiac surgery patients. Transfusion 2011;51 (8):1695-1706 10.1111/j.1537-2995.2011.03066.

16 Schöchl H, Posch A, Hanke A, Voelckel W, Solomon C. High-dose fibrinogen concentrate for haemostatic therapy of a major trauma patient with recent clopidogrel and aspirin intake. Scand J Clin Lab Invest 2010;70(6):453-457

17 Lee SH, Lee SM, Kim CS, et al. Use of fibrin-based thromboelastometry for cryoprecipitate transfusion in cardiac surgery involving deep hypothermic circulatory arrest during cardiopulmonary bypass. Blood Coagul Fibrinolysis 2010;21(7):687-691

18 Karkouti K, McCluskey SA, Syed S, Pazaratz C, Poonawala H, Crowther MA. The influence of perioperative coagulation status on postoperative blood loss in complex cardiac surgery: a prospective observational study. Anesth Analg 2010;110(6):15331540

19 Takamiya O, Hando S, Tekondo M, et al. Japanese collaborative study for fibrinogen assay: variability of the fibrinogen assay between different laboratories does not improve when a common calibrator is used. Clin Lab Haematol 2005;27(3):177-183

20 Kettner SC, Panzer OP, Kozek SA, et al. Use of abciximab-modified thrombelastography in patients undergoing cardiac surgery. Anesth Analg 1999;89(3):580-584

21 Koster A, Kukucka M, Fischer T, Hetzer R, Kuppe H. Evaluation of post-cardiopulmonary bypass coagulation disorders by differential diagnosis with a multichannel modified thromboelastogram: a pilot investigation. J Extra Corpor Technol 2001;33(3):153-158

22 Solomon C, Cadamuro J, Ziegler B, et al. A comparison of fibrinogen measurement methods with fibrin clot elasticity assessed by thromboelastometry, before and after administration of fibrinogen concentrate in cardiac surgery patients. Transfusion 2011; 51;1695-1706

23 Lang T, Toller W, Gütl M, et al. Different effects of abciximab and cytochalasin D on clot strength in thrombelastography. J Thromb Haemost 2004;2(1):147-153

24 Hendriks HG, Meijer K, de Wolf JT, et al. Reduced transfusion requirements by recombinant factor VIla in orthotopic liver transplantation: a pilot study. Transplantation 2001;71(3):402-405

25 Karkouti K, Beattie WS, Wijeysundera DN, et al. Recombinant factor VIIa for intractable blood loss after cardiac surgery: a propensity score-matched case-control analysis. Transfusion 2005;45(1):26-34

26 Niemann CU, Behrends M, Quan D, et al. Recombinant factor VIIa reduces transfusion requirements in liver transplant patients with high MELD scores. Transfus Med 2006;16(2):93-100

27 von Heymann C, Redlich U, Jain U, et al. Recombinant activated factor VII for refractory bleeding after cardiac surgery-a retrospective analysis of safety and efficacy. Crit Care Med 2005;33 (10):2241-2246

28 Friederich PW, Geerdink MG, Spataro M, et al. The effect of the administration of recombinant activated factor VII (NovoSeven) on perioperative blood loss in patients undergoing transabdominal retropubic prostatectomy: the PROSE study. Blood Coagul Fibrinolysis 2000;11(Suppl 1):S129-S132 
29 Lawson JH, Murphy MP. Challenges for providing effective hemostasis in surgery and trauma. Semin Hematol 2004;41(1) (Suppl 1):55-64

30 Ranucci M, Isgrò G, Soro G, Conti D, De Toffol B. Efficacy and safety of recombinant activated factor vii in major surgical procedures: systematic review and meta-analysis of randomized clinical trials. Arch Surg 2008;143(3):296-304, discussion 304

31 Gill R, Herbertson M, Vuylsteke A, et al. Safety and efficacy of recombinant activated factor VII: a randomized placebo-controlled trial in the setting of bleeding after cardiac surgery. Circulation 2009;120(1):21-27

32 Levi M, Peters M, Büller HR. Efficacy and safety of recombinant factor VIIa for treatment of severe bleeding: a systematic review. Crit Care Med 2005;33(4):883-890

33 Carr ME Jr, Martin EJ, Kuhn JG, Ambrose H, Fern S, Bryant PC. Monitoring of hemostatic status in four patients being treated with recombinant factor VIIa. Clin Lab 2004;50(9-10):529-538

34 Young G, Blain R, Nakagawa P, Nugent DJ. Individualization of bypassing agent treatment for haemophilic patients with inhibitors utilizing thromboelastography. Haemophilia 2006;12(6): 598-604

35 Sørensen B, Ingerslev J. Thromboelastography and recombinant factor VIla- hemophilia and beyond. Semin Hematol 2004;41 (Suppl 1):140-144

36 Sørensen B, Ingerslev J. Tailoring haemostatic treatment to patient requirements: an update on monitoring haemostatic response using trombelastography. Haemophilia 2005;11(Supp 1):1-6

37 Pivalizza EG, Escobar MA. Thrombelastography-guided factor VIIa therapy in a surgical patient with severe hemophilia and factor VIII inhibitor. Anesth Analg 2008;107(2):398-401

38 Wasowicz M, Meineri M, McCluskey SM, Mitsakakis N, Karkouti K. The utility of thromboelastography for guiding recombinant activated factor VII therapy for refractory hemorrhage after cardiac surgery. J Cardiothorac Vasc Anesth 2009;23(6):828-834

39 Levy JH, Gill R, Nussmeier NA, et al. Repletion of factor XIII following cardiopulmonary bypass using a recombinant $A$-subunit homodimer. A preliminary report. Thromb Haemost 2009;102 (4):765-771

40 Jámbor C, Reul V, Schnider TW, Degiacomi P, Metzner H, Korte WC. In vitro inhibition of factor XIII retards clot formation, reduces clot firmness, and increases fibrinolytic effects in whole blood. Anesth Analg 2009;109(4):1023-1028

41 Theusinger OM, Baulig W, Asmis LM, Seifert B, Spahn DR. In vitro factor XIII supplementation increases clot firmness in Rotation Thromboelastometry (ROTEM). Thromb Haemost 2010;104 (2):385-391

42 Khan NU, Wayne CK, Barker J, Strang T. The effects of protamine overdose on coagulation parameters as measured by the thrombelastograph. Eur J Anaesthesiol 2010;27(7):624-627

43 McLaughlin KE, Dunning J. In patients post cardiac surgery do high doses of protamine cause increased bleeding? Interact Cardiovasc Thorac Surg 2003;2(4):424-426

44 Raymond PD, Ray MJ, Callen SN, Marsh NA. Heparin monitoring during cardiac surgery. Part 1: validation of whole-blood heparin concentration and activated clotting time. Perfusion 2003;18 (5):269-276

45 Giavarina D, Carta M, Fabbri A, Manfredi J, Gasparotto E, Soffiati G. Monitoring high-dose heparin levels by ACT and HMT during extracorporeal circulation: diagnostic accuracy of three compact monitors. Perfusion 2002;17(1):23-26

46 Hashimoto K, Sasaki T, Hachiya T, et al. Real time measurement of heparin concentration during cardiopulmonary bypass. J Cardiovasc Surg (Torino) 1999;40(5):645-651

47 Despotis GJ, Santoro SA, Spitznagel E, et al. Prospective evaluation and clinical utility of on-site monitoring of coagulation in patients undergoing cardiac operation. J Thorac Cardiovasc Surg 1994;107 (1):271-279
48 Despotis GJ, Joist JH, Hogue CW Jr, et al. More effective suppression of hemostatic system activation in patients undergoing cardiac surgery by heparin dosing based on heparin blood concentrations rather than ACT. Thromb Haemost 1996;76(6):902-908

49 Shore-Lesserson L, Manspeizer HE, DePerio M, Francis S, VelaCantos F, Ergin MA. Thromboelastography-guided transfusion algorithm reduces transfusions in complex cardiac surgery. Anesth Analg 1999;88(2):312-319

50 Davidson SJ, McGrowder D, Roughton M, Kelleher AA. Can ROTEM thromboelastometry predict postoperative bleeding after cardiac surgery? J Cardiothorac Vasc Anesth 2008;22(5):655-661

51 Ak K, Isbir CS, Tetik S, et al. Thromboelastography-based transfusion algorithm reduces blood product use after elective CABG: a prospective randomized study. J Card Surg 2009;24(4):404-410

52 Royston D, von Kier S. Reduced haemostatic factor transfusion using heparinase-modified thrombelastography during cardiopulmonary bypass. Br J Anaesth 2001;86(4):575-578

53 Ranucci M, Castelvecchio S, Romitti F, Isgrò G, Ballotta A, Conti D. Living without aprotinin: the results of a 5-year blood saving program in cardiac surgery. Acta Anaesthesiol Scand 2009;53 (5):573-580

54 British Committee for Standards in Haematology, Blood Transfusion Task Force. Guidelines for the use of platelet transfusions. $\mathrm{Br} \mathrm{J}$ Haematol 2003;122(1):10-23

55 Rebulla P. Revisitation of the clinical indications for the transfusion of platelet concentrates. Rev Clin Exp Hematol 2001;5(3):288-310, discussion 311-312

56 Rebulla P. Platelet transfusion trigger in difficult patients. Transfus Clin Biol 2001;8(3):249-254

57 Ferraris VA, Brown JR, Despotis GJ, et al; Society of Thoracic Surgeons Blood Conservation Guideline Task Force; Society of Cardiovascular Anesthesiologists Special Task Force on Blood Transfusion; International Consortium for Evidence Based Perfusion. 2011 update to the Society of Thoracic Surgeons and the Society of Cardiovascular Anesthesiologists blood conservation clinical practice guidelines. Ann Thorac Surg 2011;91(3):944-982

58 Cattaneo M, Hayward CP, Moffat KA, Pugliano MT, Liu Y, Michelson AD. Results of a worldwide survey on the assessment of platelet function by light transmission aggregometry: a report from the platelet physiology subcommittee of the SSC of the ISTH. J Thromb Haemost 2009;7(6):1029

59 Peterson $\mathrm{P}$, Hayes TE, Arkin CF, et al. The preoperative bleeding time test lacks clinical benefit: College of American Pathologists' and American Society of Clinical Pathologists' position article. Arch Surg 1998;133;134-139

60 Homoncik M, Jilma B, Hergovich N, Stohlawetz P, Panzer S, Speiser W. Monitoring of aspirin (ASA) pharmacodynamics with the platelet function analyzer PFA-100. Thromb Haemost 2000;83 (2):316-321

61 Koessler J, Kobsar AL, Rajkovic MS, et al. The new INNOVANCE® PFA P2Y cartridge is sensitive to the detection of the P2Y receptor inhibition. Platelets 2011;22(1):19-25

62 Raman S, Silverman NA. Clinical utility of the platelet function analyzer (PFA-100) in cardiothoracic procedures involving extracorporeal circulation. J Thorac Cardiovasc Surg 2001;122(1): 190-191

63 Jámbor C, Weber CF, Gerhardt K, et al. Whole blood multiple electrode aggregometry is a reliable point-of-care test of aspirininduced platelet dysfunction. Anesth Analg 2009;109(1):25-31

64 Sibbing D, Schulz S, Braun S, et al. Antiplatelet effects of clopidogrel and bleeding in patients undergoing coronary stent placement. J Thromb Haemost 2010;8(2):250-256

65 Ranucci M, Baryshnikova E, Soro G, Ballotta A, De Benedetti D, Conti D; Surgical and Clinical Outcome Research (SCORE) Group. Multiple electrode whole-blood aggregometry and bleeding in cardiac surgery patients receiving thienopyridines. Ann Thorac Surg 2011;91(1):123-129 
66 Collyer TC, Gray DJ, Sandhu R, Berridge J, Lyons G. Assessment of platelet inhibition secondary to clopidogrel and aspirin therapy in preoperative acute surgical patients measured by Thrombelastography Platelet Mapping. Br J Anaesth 2009;102(4):492-498

67 Agarwal S, Coakley M, Reddy K, Riddell A, Mallett S. Quantifying the effect of antiplatelet therapy: a comparison of the platelet function analyzer (PFA-100) and modified thromboelastography (mTEG) with light transmission platelet aggregometry. Anesthesiology 2006;105(6):1287

68 Preisman S, Kogan A, Itzkovsky K, Leikin G, Raanani E. Modified thromboelastography evaluation of platelet dysfunction in patients undergoing coronary artery surgery. Eur J Cardiothorac Surg 2010;37(6):1367-1374

69 Steinlechner B, Zeidler P, Base E, et al. Patients with severe aortic valve stenosis and impaired platelet function benefit from preoperative desmopressin infusion. Ann Thorac Surg 2011;91 (5):1420-1426

70 Ying CL, Tsang SF, Ng KF. The potential use of desmopressin to correct hypothermia-induced impairment of primary haemostasis-an in vitro study using PFA-100. Resuscitation 2008;76(1):129-133

71 Weber CF, Dietrich W, Spannagl M, Hofstetter C, Jámbor C. A pointof-care assessment of the effects of desmopressin on impaired platelet function using multiple electrode whole-blood aggregometry in patients after cardiac surgery. Anesth Analg 2010;110 (3):702-707

72 Ranucci M, Nano G, Pazzaglia A, Bianchi P, Casana R, Tealdi DG. Platelet mapping and desmopressin reversal of platelet inhibition during emergency carotid endarterectomy. J Cardiothorac Vasc Anesth 2007;21(6):851-854

73 Hunt BJ, Segal H. Hyperfibrinolysis. J Clin Pathol 1996;49(12):958

74 Johansson PI, Stissing T, Bochsen L, Ostrowski SR. Thrombelastography and tromboelastometry in assessing coagulopathy in trauma. Scand J Trauma Resusc Emerg Med 2009;17;45

75 Segal HC, Hunt BJ, Cottam S, et al. Fibrinolytic activity during orthotopic liver transplantation with and without aprotinin. Transplantation 1994;58(12):1356-1360

76 Royston D. High-dose aprotinin therapy: a review of the first five years' experience. J Cardiothorac Vasc Anesth 1992;6(1):76-100

77 Levrat A, Gros A, Rugeri L, et al. Evaluation of rotation thrombelastography for the diagnosis of hyperfibrinolysis in trauma patients. Br J Anaesth 2008;100(6):792-797

78 Murkin JM, Falter F, Granton J, Young B, Burt C, Chu M. High-dose tranexamic acid is associated with nonischemic clinical seizures in cardiac surgical patients. Anesth Analg 2010;110(2):350-353 